\title{
ROBERTO ARLT O LA ESCRITURA FRONTERIZA*
}

El tema de la mesa redonda de hoy abarca aspectos cruciales de la narrativa de Arlt. Querría hacer aquí algunas consideraciones sobre la relevancia que, a mi parecer, adquieren algunas características fronterizas en la narrativa de Arlt, que apunta casi siempre, o al menos parece apuntar, a una zona o a algún aspecto común de determinados discursos, o a campos del saber o de prácticas diferenciados. Y remitirme, al final, a la vieja fórmula nomen est omen, que recorre en particular Los siete $l o \cos ^{1}$, sobre todo en el discurso del Astrólogo; fórmula en la que el nombre deviene la propia vida, el deseo, el propio presagio proyectado. Está presente en los dos tipos de discurso, el político y el literario, sobre todo en la zona fronteriza de ambos.

Pero antes querría decir dos palabras circunstanciales sobre una observación del prof. Pageaux, cuando aludió a esa ciudad tan arltiana que es Trieste. Diría que, al hablarse de los problemas de identidad y escritura, esta observación me parece aparte de pertinente, bastante sugestiva. Trieste es la ciudad de Italo Svevo que, en tantos aspectos, ha sido tocado por la crítica de un modo muy similar al de Arlt. También de Italo Svevo se decía que escribía mal; también sobre él se proyectaron, en su formación, culturas no siempre convergentes. El problema de identidad de Svevo parte ya de la elección del propio seudónimo. Recordaré aquí que la lengua de elección de Svevo (tenía origen alemán, italiano y judío) es una continua interferencia de italiano y dialecto triestino. Con un agregado, respecto de este último: el dialecto, hablado tanto por el pueblo triestino como por la alta burguesía, a la cual Svevo pertenecía, es portador de una identidad deliberada, no se siente segundo con respecto a la lengua italiana. Se trata de un instrumento que quiere marcar sólidas diferencias con la cultura italiana. Expresa la cultura mitteleuropea, su condición de catalizador de grupos étnicos diversos. Y es este indicador que Svevo escoge deliberadamente. Como lo escogerá también Umberto Saba (también con origen multiétnico) para escribir Ernesto.

Si me pareció sugestiva la observación de Trieste como ciudad arltiana es también porque aún no ha sido explorada debidamente, hasta donde sé, la influencia que la madre de Arlt, mujer de sólida cultura y originaria de un zona fronteriza mitteleuropea, pudo haber ejercido en la formación intelectual del hijo.

Algo más sobre posibles concomitancias. El metro patrón para juzgar la escritura de Svevo, en preceptistas y detractores, era el italiano literario, y al juzgar sus desviaciones (más bien, sus incisiones triestinas) se partía no de su voluntad, de su decisión deliberada de ruptura sino de un modelo general y normativo; modelo que Svevo, obviamente, cono-

\footnotetext{
* Trabajo leído en el Coloquio Internacional sobre "Roberto Arlt y la modernidad" (Universidad de París III, 1989), cuyas actas no han sido publicadas.

1 Más adelante cito según la edición de Losada ${ }^{6}, 1985$.
} 
cía más lúcidamente que sus detractores, pero cuya utilización no bastaba para dotar de un significado múltiple a su obra. Recordaré aquí también otro dato, para nada irrelevante: el descubridor de Svevo se llamaba James Joyce, irlandés y como tal enredado en problemas de identidad y escritura. Y no me refiero sólo a sus relaciones con el inglés, sino también a aquéllas con el italiano y el triestino, de lo cual dan testimonio algunos textos menores y sus conferencias en esta mezcla tan particular utilizada por un extranjero. Pienso también en algunos personajes tan arltianos que Umberto Tommasini evoca en L'anarchico triestino.

Querría partir aquí de la relevancia que asume la ficción para los personajes de Arlt. Nos encontramos como en el juego de las cajas chinas donde las posibilidades, que parecen remitir al infinito, se conjugan en un recíproco ( $y$ fatalmente limitado) abarcarse de "realidad" y ficción; la ficción enmascarada de realidad abarca a la ficción que, a su vez... Se trata menos de un juego de ficción dentro de la ficción que de la instauración de una zona de contacto entre ambas, donde los aspectos periféricos de una y otra pasan a integrar un centro complejo y determinante. La ficción tiene como materia la vida, pero ésta, a su vez, se construye con referencia a aquélla; aspectos alternantes se convierten en coagulantes. Digamos que para los personajes de Arlt el carácter de ficción, novelesco, es una moneda de prestigio. Erdosain hace gala de una autoadmiración típicamente novelesca: "¡Qué lista! ¡Qué colección! El Capitán, Elsa, Barsut, El hombre de la Cabeza de Jabalí, el Astrólogo, El Rufián, Ergueta. ¡Qué lista! ¿De dónde habrán salido tantos monstruos? Yo mismo estoy descentrado." (72). Es una reflexión robada al lector y que, por otra parte, dicta una lectura. O más adelante: “ ¡Qué colección! Barsut, Ergueta, el Rufián y yo... Ni expresamente se podía reunir tales ejemplares. Y para colmo la ciega embarazada. ¡Qué bestia!" (74). Erdosain se admira de que la realidad pueda ser "novelesca". Es, tal vez, este carácter pirandelliano el que lo induce a juzgar la realidad por lo que tiene de "novelesco", que excede la vida cotidiana. Como en su reacción ante la propuesta del Astrólogo: "Erdosain se lamentaba ya de que el "plan" fuera tan simple y poco novelesco. Le hubiera agradado una aventura más peligrosa, menos geométrica." (80).

Como en tantos otros predecesores ilustres, la "locura" de algunos personajes de Arlt tiene su relación con la ficción. Aquí los personajes se comportan, más bien, como personas que tienen conciencia de ser personajes (más que personajes que remiten a la realidad). Tienen, por otra parte, conciencia de su "locura". El prestigio, lo decimos una vez más, se cumple en función de la ficción: cuanto más se parece a una novela más parece cargado de realidad (irrealidad). El cumplimiento de la personalidad se realiza partiendo de un modelo literario. Luego, la realidad comienza a verse a través de la conformación (deformación) novelesca. Esta conciencia de sentirse "interesantes", de copiar la literatura, explicita de modo claro, el carácter, entre otros, también paródico de Los siete locos. Digamos, además, que el soporte de la ficción que prestigia la realidad puede cambiar, como en este caso referido al cine: "Aquella situación, además, le parecía muy natural; la vida adquiría ese aspecto cinematográfico que siempre había perseguido." (194). La vida asume, pues, el carácter de espectáculo, de autocontemplación. Esta proyección vital a partir de la literatura aparece en Arlt a propósito de otros personajes. Así Hipólita, "En el transcurso de los días los raros personajes de novela que había encontrado, no eran tan interesantes como en la novela, sino que aquellos caracteres que los hacían nítidos en la 
novela eran precisamente los aspectos odiosos que los tornaban repulsivos en la vida (196). O, como en este otro pasaje, Hipólita "No tendría jamás un esposo como Marcelo [personaje de una novela de Carolina Invernizzio] ni extendería su mantilla sobre la aterciopelada baranda de un palco, mientras centellan los diamantes en las orejas de las duquesas y los violines ante el proscenio chirrían suavemente" (198). Cuando el referente no es directamente literario, remite a una realidad social vista como un espectáculo literario. En la novela se alude no pocas veces a otros textos.

En cuanto al Astrólogo, el carácter fronterizo de su discurso que oscila entre la realidad y lo "novelesco", presente también en la naturaleza del discurso político y en la relación entre éste y el discurso literario, me parece un momento definitorio de la escritura arltiana. En su discurso, propone otros aspectos fronterizos. Por sobre una u otra ideología propone la ideologización de una determinada metodología revolucionaria, en este caso, fundamentalmente, la violencia. Es decir, la violencia no se convierte en una metodología dentro de o inherente a una ideología, sino que, por un juego de inversión, ideologias contrapuestas aparecen como necesariamente sometidas a la violencia. No es extraño, pues, la asociación de nombres tan distantes entre sí como Lenin y Mussolini, al igual que su homologación con aspectos coincidentes en las Vidas Pararelas: "Pues se las voy a regalar [las Vidas Pararelas] para que leyéndolas aprenda que la vida humana vale menos que la de un perro, si para imprimir un nuevo rumbo a la sociedad, hay que destruir esa vida. ¿Pero sabe usted cuántos asesinatos cuesta el triunfo de un Lenin o de un Mussolini? A la gente no le interesa eso. ¿Por qué no le interesa? Porque Lenin y Mussolini triunfaron. Eso es lo esencial, lo que justifica toda causa injusta o justa." (115). El mismo Astrólogo es consciente de esta asociación: "Y [responde el Astrólogo al Rufián] le hablo a usted con franqueza. No sé si nuestra sociedad [se refiere a la sociedad secreta] será bolchevique o fascista. A veces me inclino a creer que lo mejor que se puede hacer es preparar una ensalada rusa que ni Dios la entienda." (31). Ensalada rusa que, más adelante, aparece bastante explícita: "Seremos bolcheviques, católicos, fascistas, ateos, militaristas, en diversos grados de iniciación." (127). O "Cuando converse con un proletario seré rojo. Ahora converso con usted, y a usted le digo: Mi sociedad está inspirada en aquella que a principios del siglo noveno organizó un bandido persa llamado AbdalaAbel-Maimun." (127). Esta indiferenciación ideológica es percibida también por sus interlocutores. Erdosain "hasta sospechaba que pudiera ser un delegado bolchevique para hacer propaganda comunista en el país, ya que aquél tenía un proyecto de sociedad revolucionaria singularísimo" (28). "Unas veces [dice el Rufián Melancólico] usted cree estar oyendo a un reaccionario, otras a un cojo, y, a decir verdad, me parece que ni él mismo sabe lo que quiere." (42). O la descripción connotativa del narrador: "El guardapolvo amarillo del Astrólogo parecía la vestimenta de un sacerdote de Buda." (30). Y por último, el escepticismo que reviste la acción: "Yo sé que no puede ser, pero hay que proceder como si fuera factible." (122).

Borges dijo alguna vez que la teología pertenecía a la literatura fantástica. Por ello, no menos gustosa por sus ingredientes es, en el discurso del Astrólogo, la ensalada religiosa, que concluirá con el nuevo misticismo industrial. Del Astrólogo sabemos que frecuentaba la Sociedad Teosófica, pero su discurso es indiferenciado, y roza al propio tiempo zonas que sólo forzadamente tienen que ver con la religión. Con términos de desespe- 
räción existencial colige que "las multitudes de las enormes tierras han perdido la religión No me refiero a la católica. Me refiero a todo credo teológico" (120), "que los hombres de ésta y de todas las generaciones tienen absoluta necesidad de creer en algo. Con la ayuda de algún periódico, créame, haremos milagros. Hay varios diarios que rabian por venderse o explotar un asunto sensacional. $Y$ nosotros les daremos a todos los sedientos de maravillas un dios magnífico, adornado de relatos que podemos copiar de la Biblia." (126). La solución es "crear el misticismo industrial. Hacerle ver a un hombre que es tan bello ser jefe de un alto horno como hermoso antes de descubrir un continente. Mi políti$\mathrm{co}$, mi alumno político en la sociedad será un hombre que pretenderá conquistar la felicidad mediante la industira." (37). También en su discurso religioso, el Astrólogo apela, por una parte, a la zona común que, presente en toda religión, es, sin embargo, indiferenciada, y por otra parte a una relación particular entre religión y práctica donde la necesidad de creer se convierte en un instrumento para hacer creer.

La pureza o el ascetismo del horror, más que vinculados a una ideología de la acción, parecen connotar esa zona fronteriza ligada, de algún modo, a la indiferenciación ideológica. También el horror pasa aquí a ocupar un lugar central, a convertirse en objeto. Creo ver en Arlt un desplazamiento metonímico frecuente de estas características hacia una zona neutral que deviene primaria. Hay una correspondencia, por ejemplo entre el triunfo de la revolución y no ya el precio humano a pagar por semejante triunfo, sino la pureza y la necesidad esencial del horror. No en balde, revolución y fusilamiento son términos-pareja frecuentes. Sólo algunos ejemplos: Erdosain "Avanzaba ahora hacia la quinta del Astrólogo con el corazón batiente de entusiasmo repitiéndose la frase de Lenin, con una musiquita llena de voluptuosidad: "¡Qué diablo de revolución es ésta si no fusilamos a nadie!" (113). O el Astrólogo: "Luego pensaba en Lenin que restregándose las manos, repetía a los comisarios de los soviets: Es una locura. ¿Cómo podemos hacer la Revolución sin fusilar a nadie?" (208). O más adelante: "Comenzaremos a fusilar a todos los que puedan alborotar un poco" (216); "Dominada la cabeza, suprimido el telégrafo, fusilados los jefes, el poder es nuestro. Todo esto es una locura posible." (216). Tal vez en ninguna otra cita aparezca mejor esta idea de la pureza del horror como en ésta: "Instauraremos los autos de fe, quemaremos vivos en las plazas a los que no crean en Dios. Como es posible que la gente no se haya dado cuenta de la extraordinaria belleza que hay en ese acto... en el quemar vivo a un hombre..." (128).

El discurso del Astrólogo se sitúa en una zona de lo literario y lo político, en la cual se recurre a procedimientos y efectos comunes, que lo convierten prácticamente en un discurso fronterizo. Este aspecto puede ser igualmente importante para reflexionar sobre la escritura de Arlt, o más bien sobre las relaciones entre identidad y escritura en Arlt, sobre algunos aspectos neutrales que su escritura privilegia, como, asimismo, sobre la dudosa pertinencia del lenguaje político al lenguaje sectorial. El discurso político del Astrólogo, por ejemplo, posee elementos, en primera instancia, nítida y típicamente políticos. Insertado en un texto literario se convierte, en segunda instancia y sin perder sus características políticas en texto literario. Cualquier texto sectorial, cualquier expresión cotidiana, colocados en una perspectiva literaria cambian su naturaleza originaria. Diría por partida doble porque el discurso político es, entre todos los llamados discursos sectoriales, aún fuera de dicha perspectiva, el que más se acerca al discurso literario. 
Debo hacer aquí, necesariamente, una digresión al respecto.

Es moneda corriente incluir el lenguaje político entre los lenguajes sectoriales. Vale decir: como una jerga específica, con sus propias características y atributos. Hay, sin embargo, una diferencia que podríamos considerar sustancial. El lenguaje sectorial puede definirse, sin mayores complicaciones, a partir de su objeto, del objeto de estudio al que se refiere. Es decir, está siempre ligado a un objeto determinado, específico, a un campo del saber epistemológicamente circunscripto. Por el contrario, el lenguaje político tiene por referente, como universo del discurso, toda la vida social; penetra cada uno de los aspectos de nuestra vida. Su verdadero objeto es vario. Por otra parte, se aproxima, también, desde el punto de vista teleológico, al lenguaje literario (o al menos a aquella práctica literaria que trabaja con la persuasión, la seducción, etc.). Por estas razones hay dificultades en definir el lenguaje político a partir de un objeto determinado. En cambio puede ser definido partiendo de la finalidad específica en su utilización, finalidad en la que participan igualmente la pragmática y la retórica. Hay, además, otro aspecto que puede aproximar el lenguaje político al literario (más que al sectorial): el desplazamiento de la función primaria de la significación; en el que el significado deja paso al poder del significante. (En otra instancia está ligada a esto último la creencia de que cambiando el nombre de la realidad se cambia la realidad misma.) Las palabras se aíslan de la realidad (y en esto fundan su poder) con la intención de influir sobre la misma. Podríamos agregar aquí algunas otras convergencias posibles de ambos discursos: la necesidad de persuasión, el escamoteo de algunas verdades, la presencia de otras enmascaradas o tautológicas, obvias, etc.

Persuadir, por una parte, o comulgar, por otra, son dos vertientes características del discurso político y también de cierto discurso literario, ambas presentes en el discurso del Astrólogo. Ambas están, asimismo, ligadas al discurso religioso. Un cierto tipo de discurso va dirigido a un destinatario que no pretende alguna nueva información, sino asistir al rito de escuchar lo que ya sabe o al rito meramente sonoro; el proceso productivo del entusiasmo se basa en una complicidad que es una verdadera comunión. Algo tiene que ver esto con la alusión que hicimos antes de que los personajes de Arlt tienen a menudo como referencia personajes de ficción. Se comportan como lectores que buscan identificarse con sus personajes preferidos.

En la invasión discursiva, la realidad reconstruida (destruida) lingüísticamente adquiere proporciones de obsesión y el nomen se convierte en omen, fórmula que participa por igual de la intención política y la literaria. El discurso asume la condición de productor y movilizador de entusiasmos y en este sentido los interlocutores no expresan determinadas ideologías sino su propio entusiasmo discursivizado. Y aquí viene la tentación de recordar aquel párrafo en que Flaubert, rememorando la sensación que había experimentado al ver los Propíleos se preguntaba si no sería posible construir una obra literaria en la que las palabras, prescindentes de su significado explícito, produjeran una sensación semejante.

Persuadir y comulgar están presentes en el discurso del Astrólogo. Agregaría también asombrar, operación que se desprende de la admiración con que lo juzgan sus destinatarios. Y si bien puede decir que "Las frases importan poco a los predestinados a realizar. Son los fronterizos del genio los que engordan con palabras inútiles" (129) no se puede olvidar que sus interlocutores están siendo, en esos momentos, engordados por sus palabras. "Estos imbéciles... y yo se lo digo porque tengo experiencia... bien engañados, lo su- 
ficientemente recalentados, son capaces de ejecutar actos que le pondrían a usted la piel de gallina. Literatos de mostrador, inventores de barrio, profesores de parroquia, políticos de café y filósofos de centros recreativos serán la carne de cañon de nuestra sociedad." (129).

El discurso del Astrólogo transmite y actúa al mismo tiempo. El horror de lo que transmite termina, ante sus interlocutores, enmascarado por el entusiasmo de la actuación. Es en este pasaje a la actuación, donde el discurso está marcado de pausas o expresiones que esconden bajo sus pliegues una verdadera función fática tendiente a atrapar al destinatario. No es representativo, icónico, sino productivo, como el texto literario. Por otra parte, la lengua en que se expresa el Astrólogo tiene fuertes acentos de "oralidad", trabaja con elementos de persuasión y retóricos propios de la oratoria; el suyo es un lenguaje cargado, asimismo, de fuerte tintas teatrales. Veo también aquí un aspecto fronterizo que reclama centralidad. Como lo veo en esta cita sobre la mentira, acerca de la cual el Astrólogo elabora todo un discurso: "Pero elogie sistemáticamente a un monstruo del amor propio, y ese mismo sujeto que lo hubiera asesinado a la menor contradicción se convierte en su lacayo. Lo que debe saber es suministrarles una mentira suficientemente dosficada. Inventor o poeta, será su criado." (129). Se comprende que, por aquellos años en que discurría el Astrólogo, Hitler haya podido prometer en su campaña por la conquista del poder: "Cuando nosotros lleguemos al poder, toda mujer alemana obtendrá también un marido".

Mi intención ha sido sólo señalar algunos momentos o lugares fronterizos que, en virtud de la centralidad que asumen, desplazan los jalones originarios. Aparecen aquí como. meros indicadores de una posibilidad de hallar "zonas fronterizas" definitorias para el estudio de la identidad y la escritura de Arlt.

\section{Povzetek}

\section{ROBERTO ARLT ALI PISANJE NA STIČIŠČU}

Članek analizira nekatere elemente, ki oblikujejo pripovedništvo Roberta Arlta, argentinskega pisatelja, katerega priljubljenost $\mathrm{v}$ domovini preseneča glede na skromno poznavanje njegovega dela v evropskih krogih. Avtor članka analizira npr. odnose med stvarnostjo in fikcijo in pomembnostjo, ki jo le-ta prevzema kot notranji aspekt samih junakov, ki se vedejo kot osebe. Ta vidik predstavlja eno izmed mnogih Arltovih stičiščnih značilnosti. Te so prisotne tako v njegovem jeziku - vedno se je govorilo, da Arlt "slabo" piše - kot tudi v nenavadnem prepletanju med političnim in literarnim diskurzom $v$ govoru njegovih junakov. Avtor tega članka je to značilnost izkoristil $\mathrm{z}$ namenom, da bi razjasnil nekaj stičišč med obema diskurzoma. »V samem diskurzu dobi lingvistično rekonstruirana (uničena) stvarnost rezmerja obsesije in nomen se spremeni $v$ omen. Takšen obrazec je enako prisoten $v$ politični kot tudi literarni nameri.« Avtor je kot primer iz Arltovega opusa vzel njegov najbolj znani roman Los siete locos. 